\title{
IR Studies of Coordinatively Unsaturated Surface Compounds on Silica Gel. III. Adsorption of CO on Main Group
} Metal Ions

\author{
BERND REBENSTORF and RAGNAR LARSSON
}

Division of Inorganic Chemistry 1, Chemical Center, University of Lund, Box 740, S-220 07 Lund 7, Sweden

The stretching vibration of $\mathrm{CO}$ adsorbed on the title compounds, containing metal ions of groups I, II and III together with $\mathrm{Sn}$ and $\mathrm{Pb}$, has been measured. The frequency of this vibration spans the range from $2157 \mathrm{~cm}^{-1}\left(\mathrm{Cs}^{+}\right)$to $2232.5 \mathrm{~cm}^{-1}\left(\mathrm{Al}^{3+}\right)$. An empirical relationship between this frequency and the formal charge and ion radius as variables for the characterization of the metal ions is formulated. The maximal deviation from this equation is $6.4 \mathrm{~cm}^{-1}\left(\mathrm{Tl}^{+}\right)$or less than $9 \%$ of the frequency range. A splitting into two bands was observed only for $\mathrm{Be}^{2+}$ and $\mathrm{Mg}^{2+}$ and is explained as due to a tetrahedral configuration with two $\mathrm{CO}$ molecules similar to that observed previously with $\mathrm{Mn}^{2+}$. The single $\mathrm{CO}$ IR absorption on $\mathrm{Mn}^{2+}$ and a previously unassigned $\mathrm{CO}$ absorption band on iron (now assigned to $\mathrm{Fe}^{3+}$ ) fit well to our empirical formula. The stretching vibrations of $\mathrm{CO}$ adsorbed on other transition metal ions are compared with the present results.

In the first paper of this series ${ }^{1}$ IR spectra of $\mathrm{CO}$ adsorbed on a manganese(II) surface compound on silica gel were published together with those on cobalt(II) and iron(II). We have previously ${ }^{2,3}$ argued that the ligand field stabilisation energy might contribute to the stability of other transition metal ion $\mathrm{CO}$ complexes but not to those of manganese(II) (a $d^{5}$ electron system). Furthermore, the main group metal ions are not influenced by ligand field stabilisation. Therefore, it can be assumed that their CO complexes may have a similar stability as the manganese(II) $\mathrm{CO}$ complexes, if other conditions are similar. An investigation of such $\mathrm{CO}$ complexes should also reveal by comparison the influence of the $d$ electrons of the transition metal ions on the frequency of the adsorbed $\mathrm{CO}$ and by this throw some light on the nature of the metal ion - $\mathrm{CO}$ bond.

Similar investigations have been performed before by other workers with metal ions on zeolithes ${ }^{4}$ and on tin oxide, ${ }^{5}$ as well as with metal fluoride $\mathrm{CO}$ complexes in low temperature argon matrices. ${ }^{6}$

\section{EXPERIMENTAL}

All our samples were prepared by impregnating silica gel "Merck 7733 " 7 with a solution of the metal chloride in water to give a product with $1.0 \times 10^{-4}$ (mol metal ion)/(g silica gel) after dehydration at high temperatures $\left(1000^{\circ} \mathrm{C}\right)$ in vacuum. The metal chloride water solution was prepared from commercial p.a. metal chlorides, with the exception of $\mathrm{Cs}$, $\mathrm{Tl}$ and $\mathrm{Ga}$, where the chlorides were prepared by reacting a water solution of the sulfates with barium chloride in water or by dissolving the metal in hot hydrochloric acid $(\mathrm{Ga})$. In the case of thallium(I) and lead(II) the chlorides are probably not soluble enough in hot water to produce the surface compounds with high yield.

The dried silica gel was pressed to a sample disc and heated to $900{ }^{\circ} \mathrm{C}$ in vacuum $\left(10^{-2}\right.$ Torr $)$ in an IR cell. "Preparation method 2" was used, ${ }^{1}$ which means that together with the sample disc 0.5 to $1 \mathrm{~g}$ of the impregnated silica gel was placed in the IR cell. Further experimental details may be taken from Refs. 1 and 8.

After filling the IR cell with 80 Torr $\mathrm{CO}$ at room temperature the IR spectra were recorded at conditions also previously described. ${ }^{1,8}$ The CO spectra with beryllium and magnesium samples (Fig. 2) 
were recorded on a Perkin-Elmer spectrophotometer 180, those of the other samples on a 580 B spectrophotometer from the same manufacturer. The resolution of the IR spectra was between 0.85 and $1.4 \mathrm{~cm}^{-1}$ and the error was less than $\pm 1 \mathrm{~cm}^{-1}$.

During the measurements a CO IR absorption band was observed, which was nearly independent of the impregnation with different metal ions and could not be ascribed to $\mathrm{CO}$ physisorbed on the silica gel. This CO IR absorption is presumably due to $\mathrm{CO}$ on a metal ion present on the original silica gel. This metal ion could be removed to some 80 to $90 \%$, by heating the silica gel to $80{ }^{\circ} \mathrm{C}$ in conc. hydrochloric acid ( $38 \%)$ before use $\left(250 \mathrm{~g} \mathrm{SiO}_{2}+200\right.$ $\mathrm{ml} \mathrm{HCl}+300 \mathrm{ml} \mathrm{H}_{2} \mathrm{O}$ ). Analysis of this solution, using atomic absorption spectrophotometry, showed $0.359(\mathrm{Ca}), 0.146(\mathrm{Na})$ and $0.0038(\mathrm{~K}) 10^{-4}$ $(\mathrm{mol} \mathrm{metal}) /\left(\mathrm{g} \mathrm{SiO}_{2}\right)$.

Neither the vacuum heat treatment nor the purification with hydrochloric acid were optimized.

\section{RESULTS}

In order to make possible a comparison with other papers of this series, for instance in respect to the stability of the $\mathrm{CO}$ adsorption or the intensity of the CO IR absorption, we use the same representation of the IR spectra as before. ${ }^{1,8}$

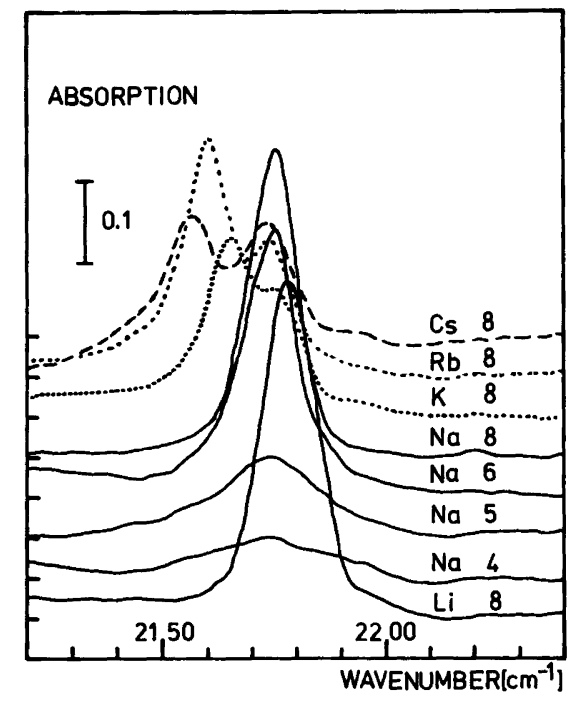

Fig. 1. IR spectra of $\mathrm{CO}$ adsorbed on alkali metal ions on silica gel. The numbers indicate the temperature and $\mathrm{CO}$ pressure $\left(8:-145^{\circ} \mathrm{C} / 1\right.$ Torr $\mathrm{CO}$, 6: $-70^{\circ} \mathrm{C} / 76$ Torr $\mathrm{CO}, 5:-40{ }^{\circ} \mathrm{C} / 78$ Torr $\mathrm{CO}, 4$ : $-10{ }^{\circ} \mathrm{C}, 80$ Torr $\mathrm{CO}$ ).
In Fig. 1 the IR spectra of $\mathrm{CO}$ adsorbed on alkali surface compounds are shown. Two different features can be noticed. The most important is that the position of one of the CO IR absorptions is decreasing in frequency rather regularly from lithium $\left(2178 \mathrm{~cm}^{-1}\right)$ to sodium $\left(2175 \mathrm{~cm}^{-1}\right)$, potassium $\left(2165.5 \mathrm{~cm}^{-1}\right)$, rubidium $\left(2160 \mathrm{~cm}^{-1}\right)$ and cesium $\left(2157 \mathrm{~cm}^{-1}\right)$. The four spectra with the sodium surface compound show the weak stability of the $\mathrm{CO}$ adsorption, which is similar for all alkali surface compounds. All these compounds have nearly no $\mathrm{CO}$ adsorbed at room temperature and 80 Torr CO pressure.

The second feature is that in the case of potassium, rubidium and cesium a second absorption band is observed at $2175.5,2174$ and $2173 \mathrm{~cm}^{-1}$, respectively. This second band may be covered by the "real" one in the case of sodium and lithium and add to the absorption band observed. One can suspect that the second band is connected to a sodium surface compound, which may be present on the silica gel before impregnation.

The change in peak intensity (the extinction coefficient) is not strong, taking into account the above discussion, although potassium and cesium have somewhat smaller bands.

In Fig. 2 the CO IR spectra with beryllium and magnesium surface compounds are reproduced.

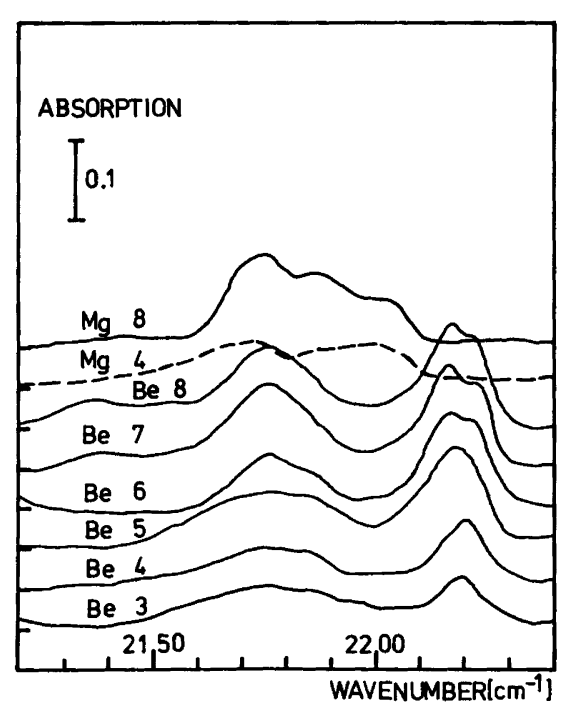

Fig. 2. IR spectra of $\mathrm{CO}$ adsorbed on beryllium and magnesium on silica gel. $\left(3: 20^{\circ} \mathrm{C} / 80\right.$ Torr $\left.\mathrm{CO}\right)$ See text to Fig. 1. 
Beryllium shows one absorption band at 2219 $\mathrm{cm}^{-1}$ at relatively high temperature, which splits at lower temperatures into two bands at 2216.5 and $2221.5 \mathrm{~cm}^{-1}$. The adsorbed $\mathrm{CO}$ corresponding to the band at $2219 \mathrm{~cm}^{-1}$ is considerably more stable than the analogous sodium CO complex in Fig. 1. The peak intensity of the IR band at $2219 \mathrm{~cm}^{-1}$ is smaller, however.

Magnesium shows a similar behaviour as beryllium with a CO IR band at $2199 \mathrm{~cm}^{-1}$ at relatively high temperatures and two bands at 2186 and 2202 $\mathrm{cm}^{-1}$ at lower temperatures. The single band (2199 $\mathrm{cm}^{-1}$ ) is here close to the band of the pair with the higher frequency $\left(2202 \mathrm{~cm}^{-1}\right)$. This is similar to the $\mathrm{CO}$ adsorption on manganese(II). where the single band is at $2190.5 \mathrm{~cm}^{-1}$ and the high frequency band of the pair is at $2192 \mathrm{~cm}^{-1}$. $^{1}$

In all spectra of Fig. 2 one can again observe a band around $2175 \mathrm{~cm}^{-1}$, however somewhat broader than in Fig. 1.

Fig. 3 shows the CO spectra with calcium, strontium and barium surface compounds, which have bands at 2176,2174 and $2167.5 \mathrm{~cm}^{-1}$, respectively. The band peaks of the $\mathrm{CO}$ adsorbed on these surface compounds move to higher wavenumbers at higher temperatures $\left(2179.5,2179\right.$ and $\left.2173 \mathrm{~cm}^{-1}\right)$, but it is not clear if this is a real effect or just produced by contamination by other metal ion

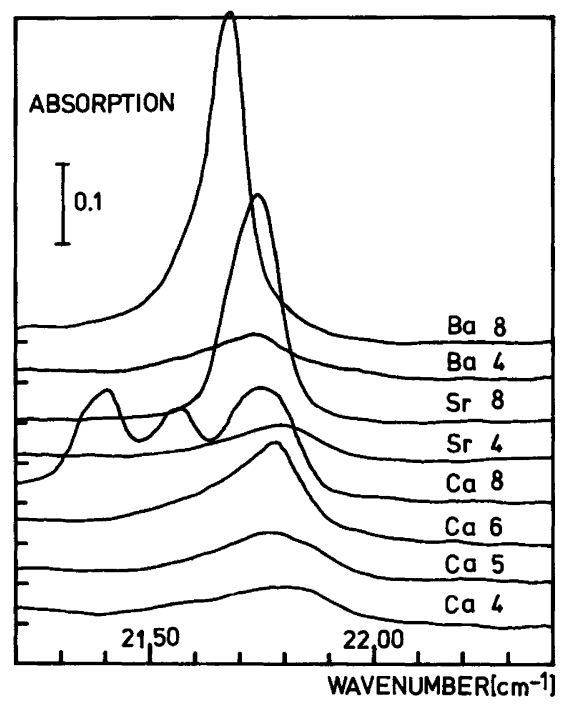

Fig. 3. IR spectra of $\mathrm{CO}$ adsorbed on calcium, strontium and barium on silica gel. See text to Fig. 1. surface compounds. The peak intensity of the $\mathrm{CO}$ IR bands is increasing from calcium to barium, while the stability of the $\mathrm{CO}$ adsorption is decreasing from beryllium (Fig. 2) to barium (Fig. 3).

In Fig. 3, spectrum Ca 8, two peaks at 2140.5 and $2156.5 \mathrm{~cm}^{-1}$ show the CO IR absorption bands of $\mathrm{CO}$ on the silica gel. which are normally subtracted in the other spectra. These bands are also often much weaker (due to our "preparation method 2") and are observed at slightly varying positions $(2138$ and $2156 \mathrm{~cm}^{-1}$ in Ref. 9).

After the investigation of the $\mathrm{CO}$ adsorption on alkali and alkaline-earth metal ions it became clear that the absorption band near $2175 \mathrm{~cm}^{-1}$ could arise from $\mathrm{CO}$ adsorbed on several metal ions such as lithium, sodium and calcium. This conclusion was based on the position and the stability of the absorption band. We therefore tried to remove the metal ions by heating the silica gel in conc. hydrochloric acid at $80^{\circ} \mathrm{C}$.

As the spectrum of $\mathrm{SiO}_{2}$,pur (Fig. 4) shows, the CO IR absorption decreased rather drastically after such treatment. It could be restored after impregnating the silica gel with sodium chloride (spectrum $\mathrm{SiO}_{2}$,pur,Na in Fig. 4). The hydrochloric acid solution (with the contaminating metal ions) was analysed having mainly calcium, sodium and (less) potassium (see experimental section).

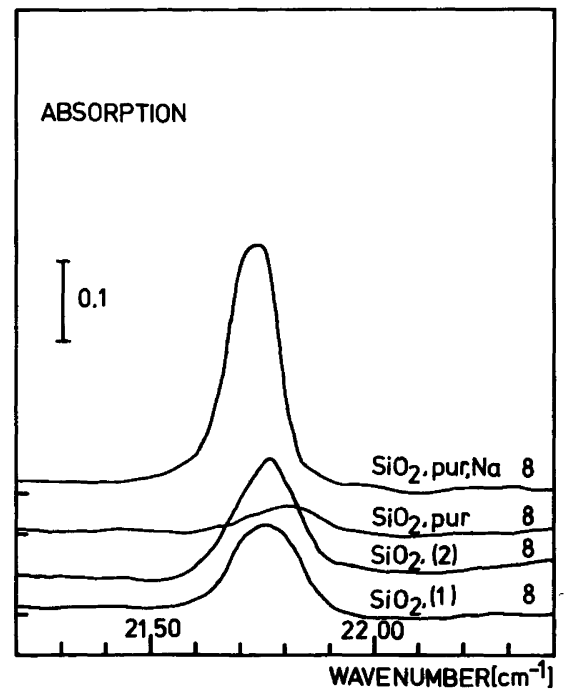

Fig. 4. IR spectra of $\mathrm{CO}$ adsorbed on untreated silica gel $(1,2)$, purified silica gel and on purified silica gel impregnated with sodium. See text to Fig. 1. 
If the peak intensity of the CO IR absorption bands in spectrum $\mathrm{SiO}_{2}(1)$ and $\mathrm{SiO}_{2}(2)$ (Fig. 4) is compared with the expected peak intensity calculated using the analytical data and the peak intensities for the IR bands of $\mathrm{CO}$ adsorbed on calcium (spectrum Ca 8, Fig. 3) and sodium (spectrum $\mathrm{SiO}_{2}$,pur,Na; Fig. 4) a difference of +10 or $+20 \%$, respectively, is found. We think that this difference might be due to inaccurate intensity measurements and/or to variations of the silica gel. (Both metal concentrations $(\mathrm{Ca}, \mathrm{Na})$ are neither listed nor guaranteed by the manufacturer.) Adding the peak intensities of the IR absorption bands of adsorbed $\mathrm{CO}$ in spectrum $\mathrm{SiO}_{2}(1)$ and $\mathrm{SiO}_{2}$,pur,Na (Fig. 4) one gets the same peak intensity as for $\mathrm{CO}$ adsorbed on the sodium surface compound in Fig. 1 (spectrum $\mathrm{Na}$ 8). The silica gel used for the spectra in the next two figures as well as in Fig. 3 were purified with hydrochloric acid (see experimental section).

No CO IR absorption band could be observed with samples impregnated with boric acid. However, samples with aluminium, gallium and indium showed CO IR bands, which had rather high wavenumbers (Fig. 5) at 2228.5, 2218.5 and $2209.5 \mathrm{~cm}^{-1}$, respectively. The top of all three bands shifted to even higher wavenumbers at low temperatures by 4,3 and $4 \mathrm{~cm}^{-1}$. Gallium showed a second CO IR

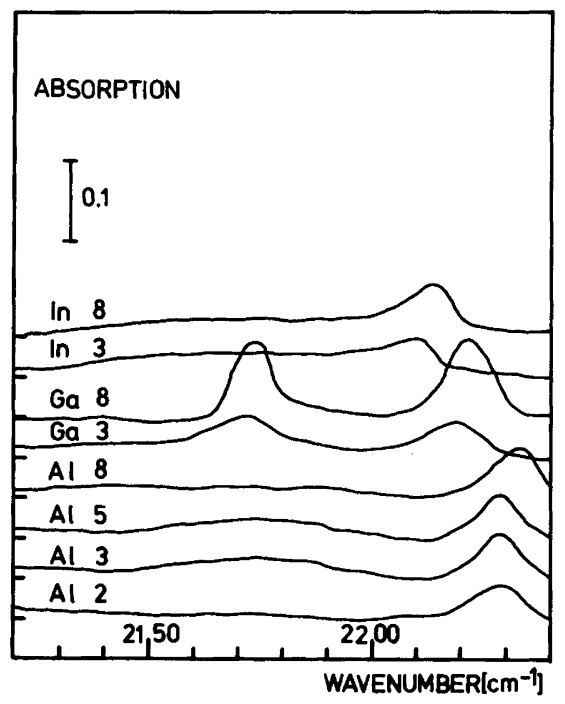

Fig. 5. IR spectra of $\mathrm{CO}$ adsorbed on aluminium, gallium and indium on silica gel. $\left(2: 20^{\circ} \mathrm{C} / 20\right.$ Torr CO). See text to Fig. 1.

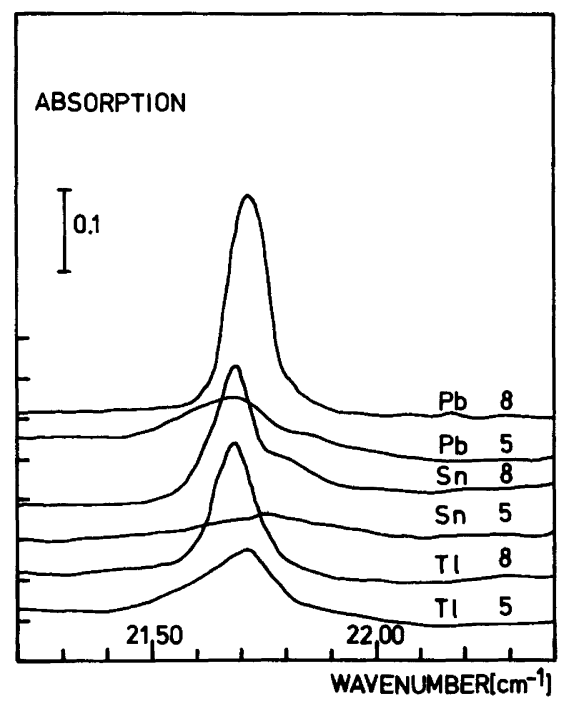

Fig. 6. IR spectra of $\mathrm{CO}$ adsorbed on thallium(I), tin(II) and lead(II) on silica gel. See text to Fig. 1.

absorption band at $2174 \mathrm{~cm}^{-1}$, which may be due to gallium(I). The peak intensity of the CO IR absorption bands on the tri-valent cations is as weak as for beryllium(II), and the stability of the $\mathrm{CO}$ adsorption complex is, as it was found for beryllium(II), relatively high and comparable to transition metal ion $\mathrm{CO}$ complexes like those of iron(II) and cobalt(II). ${ }^{1}$

In the last of the figures describing the spectra of the $\mathrm{CO}$ adsorption, the IR absorption bands of $\mathrm{CO}$ adsorbed on thallium(I), tin(II) and lead(II) are shown (Fig. 6). The peaks are at 2170, 2169 and $2171.5 \mathrm{~cm}^{-1}$ and the stability of the $\mathrm{CO}$ adsorption on these metal ions is rather low.

\section{DISCUSSION}

The basic model of $\mathrm{CO}$ adsorption describes the $\mathrm{CO}$ molecule as a weak $\sigma$ donator and a fairly good $\pi$ acceptor ${ }^{10}$ and vice versa the metal ion (or metal) as a $\sigma$ acceptor (electron pair acceptor $=$ Lewis acid) and a $\pi$ donator. In the present context, it is only of importance how these two aspects of the COmetal ion bond influence the position, intensity and half width of the $\mathrm{CO}$ stretching vibration and what effect they have on the strength of the $\mathrm{CO}$ adsorption.

In respect to the position of the CO IR absorption it is generally accepted that the $\sigma$ donor effect 
increases the frequency of the CO stretching vibration, while the $\pi$ acceptor effect decreases it. The integrated intensity of the CO IR absorption is strongly increased by the $\pi$ acceptor effect and a weaker increase due to the $\sigma$ donor effect has also been observed. ${ }^{11}$ An influence of the two effects on the half width of the $\mathrm{CO}$ stretching vibration has not been noticed. Both bonding effects increase the strength of the $\mathrm{CO}$ adsorption.

However, the above bonding mechanism is synergic, which means that a strong $\sigma$ donor effect (of the adsorbed $\mathrm{CO}$ ) will increase the electron density at the metal ion and so increase the ability of the metal ion to show a $\pi$ donor effect. Conversely, a strong $\pi$ donation from the metal to the $\mathrm{CO}$ molecule can strengthen the $\sigma$ donor properties of $\mathrm{CO}$. Such a mechanism, giving contributions to the $\mathrm{CO}$ frequency shift in opposite directions, may cause only a small change of the $\mathrm{CO}$ frequency for the transition metal ion complexes ( $d$ electrons), but will enhance the stability of the $\mathrm{CO}$ complexes.

In discussing our results of the $\mathrm{CO}$ adsorption on main group metal ion surface compounds we will refer to the above remarks in order to separate the two bonding effects, of which the $\sigma$ donor effect of the $\mathrm{CO}$ molecule should be the main contribution to the change of the $\mathrm{CO}$ stretching vibration from that of the $\mathrm{CO}$ gas $\left(2143 \mathrm{~cm}^{-1}\right)$.

The frequency of the IR absorption of CO adsorbed on cations is often described in reference to the Coulomb law, i.e., depending on the formal charge $(Z)$ divided by the square of a distance. ${ }^{4-6}$
This distance is normally the sum of the ionic radius $\left(R_{\mathrm{i}}\right)$ of the cation and a distance derived from the $\mathrm{CO}$ molecule. However, such a Coulomb law approach overlooks the $\pi$ donor effect of the transition metal ions and, furthermore, does not take into account the vibration coupling between the $\mathrm{M}-\mathrm{C}$ vibration and the $\mathrm{C}-\mathrm{O}$ vibration, which will always be present. ${ }^{12}$ In our systems the $\mathrm{M}-\mathrm{C}$ vibration is not observable due to the strong absorption of the silica gel support in the IR region, where this vibration should be expected. We had, therefore, to choose to use the ionic radius and formal charge only as variables of the cations in describing the spectra of $\mathrm{CO}$ adsorbed on the metal ion surface compounds.

In Fig. 7 the ionic radius ${ }^{13}$ (Pauling) is plotted against the frequency of the IR absorption of adsorbed $\mathrm{CO}$. The cations can be represented by three straight lines according to their formal charge. Using the simple formula for a straight line one gets eqn. (1).

$\bar{v}=\vec{v}_{\mathrm{CO}_{\text {gas }}}+a-b R_{\mathrm{i}}$

The constant $a$ has values of 49,90 and $113 \mathrm{~cm}^{-1}$ and the constant $b$ values of $20.7 \times 10^{8}, 51.5 \times 10^{8}$ and $58.6 \times 10^{8} \mathrm{~cm}^{-2}$. The three straight lines in Fig. 7 are calculated by a least squares procedure using IR frequencies of $\mathrm{CO}$ adsorbed on uni-valent ( $\mathrm{Li}, \mathrm{Na}, \mathrm{K}, \mathrm{Rb}, \mathrm{Cs}$ ), bi-valent (Be, $\mathrm{Mg}, \mathrm{Ca}, \mathrm{Sr}, \mathrm{Ba}$ ) and tri-valent surface cations (Al, Ga, In, crosses).

A combination of the straight lines for the uni-

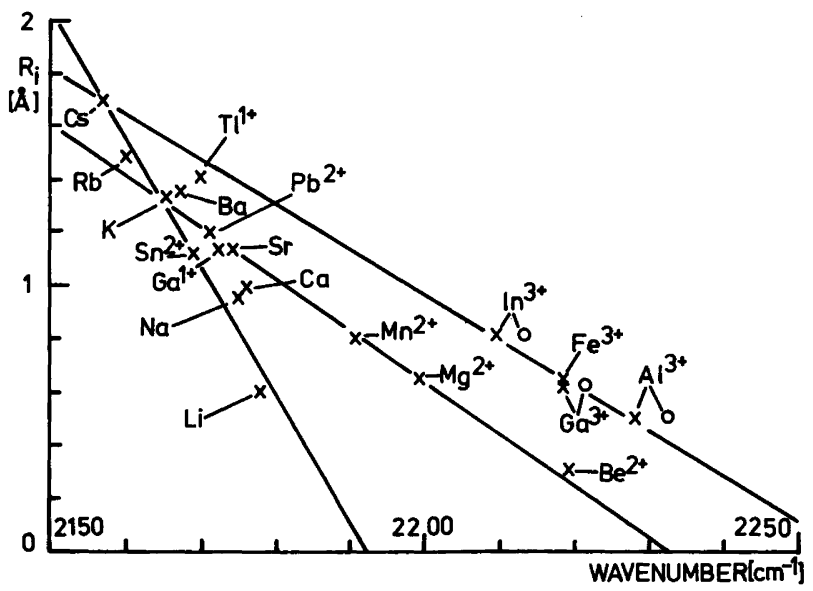

Fig. 7. Plot of ionic radius ${ }^{13}$ versus frequency of the IR absorption of adsorbed $\mathrm{CO}$. The straight lines are calculated by a least squares procedure. See discussion. 


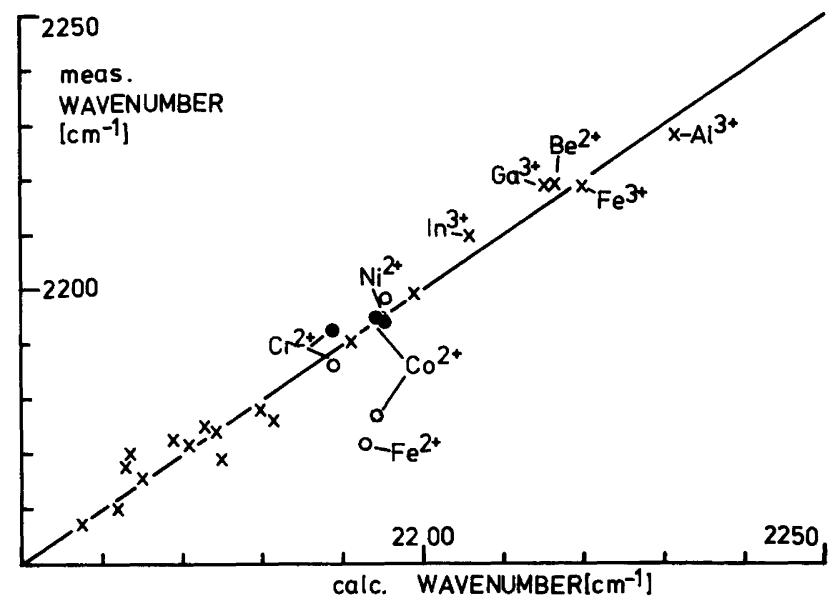

Fig. 8. Plot of measured frequency versus frequencies calculated by the empirical eqn. (2). Frequencies of trans (open circles) and cis (full circles) transition metal ion surface compounds with one adsorbed $\mathrm{CO}$ molecule are added. See discussion.

valent and the bi-valent cations using the formal charge (Z) gives eqn. (2).

$\bar{v}=\bar{v}_{\mathrm{CO}_{\text {gas }}}+a+b Z+c R_{\mathrm{i}}+d Z R_{\mathrm{i}}$

The constants have the values $9.5 \mathrm{~cm}^{-1}(a), 40 \mathrm{~cm}^{-1}$ (b), $10.1 \times 10^{8} \mathrm{~cm}^{-2}(c)$ and $-30.8 \times 10^{8} \mathrm{~cm}^{-2}(d)$.

In Fig. 8 the measured frequency values for adsorbed $\mathrm{CO}$ are plotted against those calculated using eqn. (2). This empirical formula is valid also for the tri-valent cations, as can be seen from the figure. It is, however, not clear if a similar extension of the formal charge range as made for the tri-valent cations, is also possible in the inverse direction, i.e., to metal atoms. The largest deviations of the measured $\mathrm{CO}$ frequencies from eqn. (2) are $+6.4\left(\mathrm{Tl}^{+}\right),-6.0\left(\mathrm{Sn}^{2+}\right)$ and $-5.6 \mathrm{~cm}^{-1}\left(\mathrm{Ca}^{2+}\right)$, which means that all measured $\mathrm{CO}$ frequencies lie within $9 \%$ of the present $\mathrm{CO}$ frequency range from 2157 to $2228.5 \mathrm{~cm}^{-1}$. The frequency deviations show roughly a symmetrical Gauss curve. When now turning to discuss the frequencies of $\mathrm{CO}$ adsorbed on transition metal ions, we will rely on these findings and calculate the $\mathrm{CO}$ frequencies from eqn. (2) to represent a similar-sized ion without valence d-electrons.

$C O$ on transition metal ions. In the introduction we have used the argument that in the case of manganese(II), with no ligand field stabilisation energy, the stability of the $\mathrm{CO}$ adsorption complex might be similar to that of the main group metal ions. This is, in fact, the case as can be seen by comparing the temperature and pressure dependence of the spectra of $\mathrm{CO}$ adsorbed on manganese(II) ${ }^{1}$ and magnesium(II) (see results). With eqn. (2) we can now calculate the manganese(II) $\mathrm{CO}$ frequency $\left(2191.3 \mathrm{~cm}^{-1}\right)$, which is nearly the same as that observed $\left(2190.5 \mathrm{~cm}^{-1}\right)$. One can conclude from this small deviation that a half filled $d$ electron shell has no noticable effect on the frequency of adsorbed $\mathrm{CO}$ and on the stability of the $\mathrm{CO}$ adsorption.

This line of argument can be extended to another $d^{5}$ ion, namely iron(III). Previously we have observed a CO IR absorption band on iron impregnated samples at $2218.5 \mathrm{~cm}^{-1}$, which we, at that time, could not assign. ${ }^{1}$ As Fig. 7 shows, this band fits nicely to the straight line for the tri-valent cations. Calculating the $\mathrm{CO}$ frequency according to eqn. (2) gives $2219.3 \mathrm{~cm}^{-1}$, which is again in good agreement with the observed $\mathrm{CO}$ frequency. The previous assignment of a band at $2165-2169 \mathrm{~cm}^{-1}$ to an iron(III) CO complex is somewhat "softened" by this argument. A future investigation of the trivalent transition metal surface cations will hopefully clarify this disagreement.

Before we discuss the CO IR absorptions on other transition metal ions, it is necessary to put forward models for the main group metal ion surface compounds and their $\mathrm{CO}$ complexes. In the case of the uni-valent cations, only one configuration is possible for the surface compound, as can be seen 


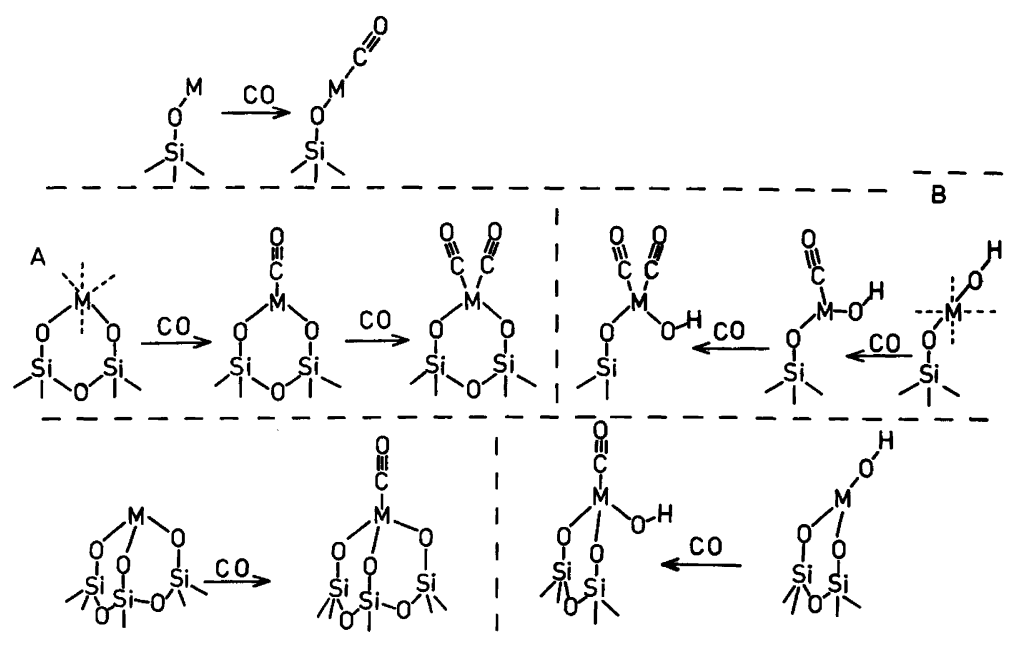

from the scheme. For the bi-valent cations two possibilities exist, namely a trans configuration $\left(-\mathrm{O}-\mathrm{M}-\mathrm{O}-\right.$ angle $\left.180^{\circ}\right)$ and a cis configuration (OMO angle less than $180^{\circ}$, most likely between 120 and $90^{\circ}$ ). This has been proved for the transition metal ions, ${ }^{1,8}$ but for the main group metal ion $\mathrm{CO}$ complexes (and those of manganese(II)) these two configurations may lead to the same $\mathrm{M}-\mathrm{CO}$ configuration, as shown in the middle of the scheme. The structure A models the cis configuration and the structure B the trans configuration. On the basis of previous discussions ${ }^{1,8}$ the structure $A$ in the scheme is most likely present under our preparation conditions ("preparation method 2").

For the tri-valent surface cations three configurations can be expected with symmetries $D_{3 h}$ ("Star"), $C_{3 v}$ ("Top") and $C_{2 v}$ ("T"). ${ }^{14}$ The "Top" configuration is most likely present with main group metal ion surface compounds (shown in the scheme), but a detailed discussion of the IR vibrations of $\mathrm{CO}$ adsorbed on tri-valent surface cations in respect to the different configurations should be postponed to the investigation of tri-valent transition metal cations, where one can expect more examples of different $\mathrm{CO}$ complexes.

Assuming that only such species as depicted in the scheme are present, it becomes clear that the single frequency of the $\mathrm{CO}$ stretching vibration in Figs. 7 and 8 refers to the complexes with only one $\mathrm{CO}$ molecule adsorbed.

In order to compare the CO IR absorptions of the transition metal $\mathrm{CO}$ complexes [except those of manganese(II)] it is necessary to discuss the cis and trans surface compounds separately. For the trans configuration there is at present only for chromium(II) evidence that the complex with only one $\mathrm{CO}$ molecule really exists. ${ }^{15,1}$ The frequency of this adsorbed $\mathrm{CO}$ coincides with the frequency of the IR active vibration of the complex with two $\mathrm{CO}$ molecules. We assume that this behaviour is general also for the other trans surface compounds of bi-valent transition metal ions.

As one can see from Fig. 8, these frequencies (open circles) lie partly on line with the main group metal ions (chromium(II) and nickel(II)) as well as differ considerably from the line (cobalt(II) and iron(II)). In the latter two cases the measured frequencies are 17 and $21 \mathrm{~cm}^{-1}$ below the calculated ones, which is a considerably larger deviation than for any main group metal surface ion.

Previously $^{2,3}$ we have found that the stability of the $\mathrm{CO}$ complexes of the above ions increases with increasing frequency of the CO IR absorption. This was stated before the cis-trans isomerism of the bi-valent surface compounds was established ${ }^{1,8}$ and so some explanatory remarks are necessary. It is clear that in the case of nickel(II) and iron(II) the trans surface compounds are the $\mathrm{CO}$ adsorption centers. With chromium(II) the cis compound is present, ${ }^{1}$ but most likely only to some 10 to $20 \%$, so that the $\mathrm{CO}$ complex stability refers (only) mainly to the trans surface compound. In the case of cobalt(II) the cis surface compound is exclusively present, but the $\mathrm{CO}$ complex of the trans surface compound has in this special case similar stability as that of the cis surface compound, which can be 
seen from the CO IR spectra in Ref. 1.

The above arguments now point to the conclusion that the above-mentioned increase of the stability of the $\mathrm{CO}$ complexes with increasing $\mathrm{CO}$ stretching frequency is only valid for the trans surface compounds. If we now combine this correlation of the $\mathrm{CO}$ stretching frequency and the stability of the CO complexes with the effects of $\sigma$ acceptor and $\pi$ donor abilities of the transition metal ions, it is obvious that in this case the stability of the $\mathrm{CO}$ complexes is also mainly caused by a $\sigma$ acceptor effect of the metal ion similar to that of the main group metal ions.

On the other hand, however, the stability of the above CO complexes is considerably larger than that of main group metal ions of the same formal charge and comparable ion radius. This disagreement can possibly be explained with the assumption that the transition metal ion $\mathrm{CO}$ complexes use to some extent the synergic bonding mechanism.

The assignment of the frequency of the cis surface complexes with only one $\mathrm{CO}$ molecule is as difficult as that for the trans surface compounds. Only in the case of cobalt(II) has such an assignment been attempted before. ${ }^{1}$ We simplify again, with the assumption that the expected frequency is close to that with the higher wavenumber of the cis complex with two CO molecules, which is the case with cobalt(II) (2195 to $\left.2189 \mathrm{~cm}^{-1}\right)$. Three of these frequencies are shown in Fig. 8 (full circles), which all lie relatively close to the line of the main group metal ions.

The stability of the cis $\mathrm{CO}$ complexes with two $\mathrm{CO}$ molecules adsorbed diffuses, however, in a similar way as the trans surface complexes, so that one can propose a difference in the bonding mechanism of the $\mathrm{CO}$ adsorption on trans and cis surface compounds of transition metal ions.

Summarising, one can conclude that the frequencies of adsorbed $\mathrm{CO}$ are not drastically different between main group and transition metal surface ions with the formal charge two and comparable ionic radius, while the stability of the $\mathrm{CO}$ complexes is considerably higher for transition metal surface compounds.

Integrated intensity of the COIR absorption. In respect to the integrated molar intensity of the $\mathrm{CO}$ IR absorption a decrease with increasing frequency can be concluded from Fig. 9. It should, however, be kept in mind that Fig. 9 is based on the assumption that the formation of the surface compounds is similar in quantity to those of transition metal ions (75\% of the overall metal content), which is not proved. In addition, the formation of the $\mathrm{CO}$ complexes with low frequencies (below $2170 \mathrm{~cm}^{-1}$, low stability) may not be completed at the low temperatures used in our measurements. Nonetheless, we propose that the broken line in Fig. 9 represents some upper limit for the integrated intensity of the $\mathrm{CO}$ IR absorption of $\mathrm{CO}$ adsorbed on main group

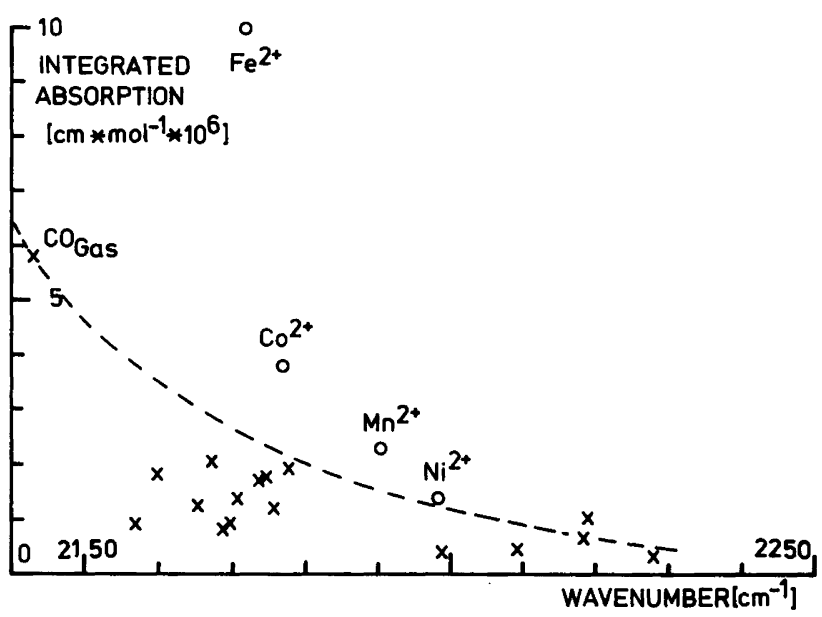

Fig. 9. Plbt of integrated intensity of the IR absorption of adsorbed CO against frequency of the CO IR absorption. The broken line is thought to be an upper limit of the integrated intensity of $\mathrm{CO}$ adsorbed by main group metal ions on silica gel. 


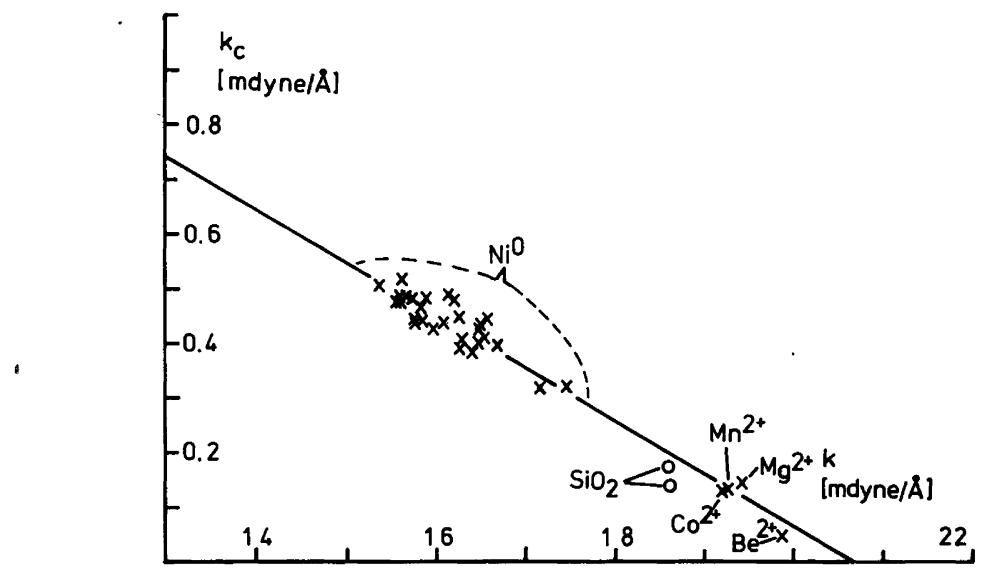

Fig. 10 Plot of the stretching interation $\mathrm{CO}-\mathrm{CO}$ constant $k_{\mathrm{c}}$ versus stretching force constant $k$ for tetrahedral complexes with two $\mathrm{CO}$ molecules. The crosses in the middle represent nickel(0) complexes from Ref. 17. For further details see discussion.

surface compounds. Although we used the same equation for the calculation of the integrated intensity (eqn. (4) in Ref. 11) we find an inverse trend with frequencies higher than that of $\mathrm{CO}$ gas $\left(2143 \mathrm{~cm}^{-1}\right)$, which is contrary to the results reported by Seanor and Amberg. ${ }^{11}$

Two items support the general correctness of our calculation of the integrated intensity: (1) The integrated intensity of the $\mathrm{CO}$ molecule ${ }^{11,16}$ itself is $5.8 \times 10^{6} \mathrm{~cm} \mathrm{~mol}^{-1}$, which is only about three times higher than our values for the IR absorption band of $\mathrm{CO}$ adsorbed on main group metal ion surface compounds. Support for the dashed line comes also from the known fact that the integrated intensity of $\mathrm{CO}$ vibrations in carbonyls is very high, for example $\mathrm{Ni}(\mathrm{CO})_{4}\left(2057 \mathrm{~cm}^{-1}\right)$ has a integrated integrated intensity of $320\left(\mathrm{CCl}_{4}\right)$ or $456 \times 10^{6} \mathrm{~cm}$ $\mathrm{mol}^{-1}$ (THF). ${ }^{16}$ (2) If one calculates the integrated intensity of the IR absorption band for $\mathrm{CO}$ adsorbed on $\mathrm{Ni}^{0}$ from the figures in Ref. 8, an integrated intensity of $570 \times 10^{6} \mathrm{~cm} \mathrm{~mol}^{-1}$ is found, which is close to the comparable values for $\mathrm{Ni}(\mathrm{CO})_{4}$.

As can be seen in Fig. 9, the integrated intensity of the $\mathrm{CO}$ stretching vibration is close to the dashed line representing the main group metal ion surface compounds in the case of trans cobalt(II), manganese(II) and trans nickel(II) and much higher in the case of trans iron(II) (and, presumably, trans chromium(II)).

In a previous paper of this series ${ }^{8}$ an empirical dependence of the stretching interaction $\mathrm{CO}-\mathrm{CO}$ constant ("splitting force constant") $k_{\mathrm{c}}$ of a tetra- hedral configuration with two $\mathrm{CO}$ molecules on the stretching force constant $k$ of the two $\mathrm{CO}$ molecules of such a configuration was shown. In Fig. 10 the values for the magnesium(II) and beryllium(II) complexes are plotted in a similar way, together with those for tetrahedral nickel(0) complexes ${ }^{17}$ (slightly selected) and two values for the cobalt(II) and manganese(II) $\mathrm{CO}$ complexes. The least squares straight line through these values (crosses in Fig. 10) hits the force constant axis at $20.66 \mathrm{mdyne} / \AA$ or $2262 \mathrm{~cm}^{-1}$.

The two open circles in Fig. 10 represent the IR absorption bands of $\mathrm{CO}$ physisorbed on the silica gel from above and are relatively close to the straight line. We take this as some evidence that the physisorbed CO is adsorbed at a tetrahedral system, which is most likely the oxygen atom of siloxan bridges on the silica gel surface $(-\mathrm{Si}-\mathrm{O}-\mathrm{Si}-)$. This would mean that physisorbed $\mathrm{CO}$ is not bonded by an undirected force, as van der Waals forces are normally interpreted, but by a tetrahedral system with relatively directed bonds.

Acknowledgement. We thank the Swedish National Sciences Research Council for support.

\section{REFERENCES}

1. Rebenstorf, B. and Larsson, R. Z. Anorg. Allg. Chem. 453 (1979) 127.

2. Rebenstorf, B. Acta Chem. Scand. A 32 (1978) 195. 
3. Rebenstorf, B. and Larsson, R. Inorg. Nucl. Chem. Lett. 14 (1978) 381.

4. Angell, C. L. and Schaffer, P. C. J. Phys. Chem. 70 (1966) 1413.

5. Harrison, P. G. and Thornton, E. W. J. Chem. Soc. Faraday Trans. 1, 74 (1978) 2703.

6. Hauge, R. H., Gransden, S. E. and Margrave, J. L. J. Chem. Soc. Dalton Trans. (1979) 745.

7. Krauss, H. L. and Naumann, D. Z. Anorg. Allg. Chem. 430 (1977) 23.

8. Rebenstorf, B. and Larsson, R. Z. Anorg. Allg. Chem. 453 (1979) 139.

9. Zecchina, A., Garrone, E., Ghiotti, G. and Coluccia, S. J. Phys. Chem. 79 (1975) 972.

10. a. Little, L. H. Infrared Spectra of Adsorbed Species, Academic, London, New York 1966, p. 67 ; b. Cotton, F. A. and Wilkinson, G. Advanced Inorganic Chemistry, 2nd Ed., Interscience, New York 1968, p. 728; c. Purcell, K. F. and Kotz, J. C. Inorganic Chemistry, W. B. Saunders, Philadelphia 1977, p. 861.

11. Seanor, D. A. and Amberg, C. H. J. Chem. Phys. 42 (1965) 2967.

12. Okawa, T., Soma, M., Bandow, H. and Uchida, K. J. Catal. 54 (1978) 439.

13. Kneen, W. R., Rogers, M. J. W. and Simpson, P. Chemistry, Addison-Wesley, London 1972, p. 796.

14. Ref. 10. c, p. 151.

15. Westphal, U., Diss., Freie Universität Berlin, West Berlin 1977.

16. Hush, N. S. and Williams, M. L. J. Mol. Spectrosc. 50 (1974) 349.

17. Adams, D. M. Metal-Ligand and Related Vibrations, Edward Arnold, London 1967, pp. 156, 157.

Received October 25, 1979. 